\title{
REFLECTIONS
}

\section{Family Medicine's Identity: Being Generalists in a Specialist Culture?}

\author{
Howard F. Stein, PbD \\ Department of Family and Preventive Medi- \\ cine, University of Oklahoma Health Sci- \\ ences Center, Oklahoma City, Okla
}

\begin{abstract}
Family medicine has been in conflict about whether it is a specialty or a generalist discipline. Although for a time the family was offered as a solution to family medicine being marginalized in biomedicine, a more biomedical focus prevailed. As a result, the practice of family medicine came more to resemble the world of biomedicine despite an insistence on the discipline's distinctiveness. Ways to avoid identity pitfalls in the future might be to seek solutions that do not promise to solve our identity problem once and for all, to refrain from adopting generalized slogans that do not encourage critical thinking, to practice what we preach, to accept that specialization is part of the American cultural ethos, and to embrace reflective practice.
\end{abstract}

Ann Fam Med 2006;4:455-459. DOI: 10.1370/afm.556.

\section{THE STRUGGLE FOR IDENTITY}

7 he uncertain identity and future of family medicine as a discipline is on the minds of many in family medicine in recent years-practitioners, academicians, researchers, and policy makers alike. The Future of Family Medicine report ${ }^{1}$ attests to the emotional valence of defining and redefining family medicine. This essay is a critical reflection on the discipline of family medicine from the perspective of a long-time participantobserver. ${ }^{2-7}$ I examine the relationship between family medicine's struggle for identity and the dominant American culture within which that struggle occurs. This struggle is evidenced by the lack of consensus around family medicine's core values and role in the health care system.

The new (renewed) search for identity within family medicine is, in fact, quite old. There have been many different solutions proposed in an effort to resolve the identity crisis. I argue that the theme of the conflict between generalist and specialist identity is a driving force that underlies many issues, problems, decisions, and choices within family medicine.

\section{COMPETING IDENTITY MODELS IN FAMILY MEDICINE}

From the outset family medicine has struggled between the polarities of wanting to be similar to most, if not all, of the other allopathic disciplines (specialties) and wanting to pursue a distinct voice as a generalist discipline rooted in a keen social conscience. This dynamic underlies the distinction between wanting to be part of the mainstream American biomedical culture and wanting to be a counterculture. This undercurrent permeates the models held by family physicians about their discipline.

There are at least 3 competing operational models or narrative structures of identity within family medicine. For some in the discipline, these models are adhered to consistently. For others, they are claimed and asserted situationally, if not opportunistically, in the ongoing competition 
for power, authority, status, and funds. These models are meant as only an approximate map for the constantly changing territory of family medicine.

\section{Family Medicine as an Ethos}

Family medicine can be defined as a coherent ethos-a world view; a philosophical, ideal whole; an ahistorical doctrinal core; an integrative, holistic attitude toward life that is reflected and practiced in biomedicine. Here family medicine is both exemplar and champion of the biopsychosocial model, the contextually-based practice, and in particular seeks to advance social justice by providing health care to underserved, at-risk groups.

\section{Family Medicine as Role Traits}

Family medicine can be described as a relatively stable, pragmatic, collection or assortment of role traits, additive or subtractive, as in, "We do this," and "We don't do that." Adherents to this model tend to pay attention to market forces, as well as to personal practice preferences (eg, performing such medical procedures as colposcopy, flexible sigmoidoscopy, and low-risk delilvery). A variant on this model is family medicine as an approximate, statistical aggregate of ideas and practices, a range of activity, wherein no one does it all. As a group, however, everyone keeps within this range of ideas and practices, which continue to change historically (eg, "Some of us deliver babies, some of us see old people, some of us take time to counsel patients and families psychologically, and what we do together makes up what family medicine is.").

\section{Family Medicine as Gatekeeper}

Family medicine as gatekeeper to the health care system is a most recent role. Adherents of this model tend to envision family medicine as pure adaptation to current market needs. This model focuses on how family medicine exists in the health care system.

Each of these models of family medicine plays a part in the tension between specialist and generalist identity in family medicine.

\section{FAMILY MEDICINE CULTURE AND IDENTITY IN THEORY AND OPERATION}

To explore identity conflict throughout the history of family medicine, we must first ask, What does identity look like, sound like? How does one recognize identity? ${ }^{8-11}$ How do these cultural processes manifest themselves in family medicine?

Who we are and claim to be is bound up with who we insist we are not. Consider the following 2 examples that illustrate ways in which we identify ourselves by who we are not.
A family medicine faculty colleague once explained to me the distinctiveness of family medicine in relation to other biomedical disciplines: "We're not just a bunch of little pediatricians, little internists, or little psychiatrists. We're real doctors with our own way of seeing things and doing things. We've got a specialty of our own right." He was identifying his personal self with a professional group, and then emphasizing that his group possessed a distinct boundary and special cultural content. He was using the metaphor of relative size to argue his point. It was as if to say that family doctors are grown-ups, real people, independent adults, not easily ignored, dependent children, not miniatures and lesser versions of other specialists. He was defining family medicine by contrasting it with other biomedical professions. He was attempting to resolve conflicting elements of identity by emphasizing that family doctors are as big as any other physicians.

Consider a second we-they example. Family medicine had its origins, at least in part, in a movement that embodied the social reformism and generalist idealism of the 1960s. As the discipline entered the new millennium, it had become a highly successful part of the biomedical-specialist institutional structure in both academics and practice. Initially critical of the establishment, family medicine is now part of the establishment. Increasing numbers of its adherents bristle at notions of reform and social movement, let alone counterculture. They associate these issues with images of social misfits and hippies rather than with their selfimage as successful physicians having arrived professionally and economically in mainstream America.

Finally, as family physicians imagine their future, there is widespread fear that within the primary care movement, family medicine might be absorbed (for example, into internal medicine), lose its identity, and disappear. Here, as in the first example, identity affirmation is tied up with repudiation ("We are family doctors, not internists."). More broadly, this conflict within family medicine is a manifestation of the far wider American cultural conflict between wanting to be mainstream (to fit in) and wanting to be distinctive.

\section{A HISTORY OF CONFLICT}

Identity, then, is not some peripheral issue; it takes us to the heart of the history of family medicine. Since its inception, family medicine has been a group identity in search of and in conflict over content. From the outset family medicine has had core values, but that core itself has been conflict-ridden and far from uniform or based on consensus. Furthermore, much of the conflict that appears on the surface to be primarily political or economic originates more deeply from issues of personal 
and group identity and boundaries. I argue that these core conflicts better characterize the history of family medicine than do fundamental core value(s) to which the field has adhered or from which it has deviated. A central-if not the central-core conflict is between generalism and specialization.

Although family physicians would agree that family medicine exists, precisely what it comprises is the subject of debate. The discipline has long been bereft of a distinctive or unique medical technology, theory, diseaseunit, life stage, or organ system. For family physicians, one solution to this sense of deficiency is the wish to see oneself and be seen as a specialist. From the outset, many family physicians and their teachers have claimed to be specialists rather than generalists, but in what does that specialty, specialization, and specialness lie? Even the choice of specializing is not without conflict.

For many family doctors, to specialize in the physician-patient relationship, in their patients as whole persons, or in persons in social contexts is not sufficiently biomedical. What one specializes in (content) is as important as the claim to be a specialist. At the core of its very American identity struggle is family medicine's search for legitimacy. In fact, as Stephens writes: "The eagerness for legitimacy and excellence, as defined by the medical schools, may turn out to have been a fatal flaw in family practice, which wanted acceptance and approval at any cost." 12

In American professional and popular culture alike, the importance of being a specialist rests upon the image and magical aura of the expert. The cultural argument goes that there is so much to know, and no one can know everything. To be recognized as competent, one must be an expert in a limited area of knowledge. As the culturally positivist argument continues, fragmentation is therefore the price we must pay for the benefits of expertise. In such a cultural climate, to claim expertise in contextual breadth and relationship is held suspect, if not regarded as an oxymoron. In such waters, the generalist swims against a swift cultural current.

\section{WHAT'S IN A NAME?}

Throughout the history of family medicine, the ideological distinction between generalist and specialist has created a great divide. This polarity has been played out in the distinction between family doctor, the new breed of specialist, vs general practitioner, the old guard. Struggle within individuals and between generational cohorts takes place over which of the pair is good and which is bad or at least devalued.

Increasingly, within the discipline, general practitioner and any form of clinical generalism are regarded with disdain and contempt. John Frey, however, has been the exception. ${ }^{13}$ Family medicine predecessorsthe founding fathers and mothers who were not residency trained, who were grandfathered into the new specialty by virtue of seniority-are cast in the image of being less than legitimate and inferior. Much of the conflict is intergenerational. In a distinctly American style, family medicine heirs insist on being self-made, not descendants of professional fathers and mothers. About a decade ago at a family medicine meeting, I was sternly rebuked when I advocated the virtues of clinical generalism. "Generalism is out!" I was scolded. Family medicine's future, they contended, lay in carving out the specialist role, specifically as gatekeeper to the health care system.

\section{Professional Identity and the Importance of Family}

The ideological conflict between generalism and specialization has long been mirrored in the role that family plays in family medicine training and practice and in the very definition of the field. Family medicine has struggled from its inception to possess something of high status that is uniquely its own, not borrowed, not grafted.

For many in family medicine, the family became for a time the putative symbolic organ system, unit of care unique to family medicine-its distinctive cultural feature. At STFM meetings in the early 1980s, the slogan Think Family! was often repeated. For many academic family physicians and behavioral science faculty in the 1980s, the family became the magical mantra that would confer specialty status on their discipline.

During this time, many academic family physicians hoped that family theory and family therapy would become their discipline's hard science. They hoped that its rigor and status would redeem family medicine from its scientific marginality. In theory this would make family medicine into real, legitimate medicine, an equal with the other biomedical specialties. The ideology of the family was a means toward that end.

The place of the family in family medicine raises a broader issue. At the center of many conflicts within family medicine have been the nature of the boundary between real medicine (that is, organic) and family, and whether psychosocial medicine (eg, family, culture, community, workplace, economics) is located within or outside medicine. These conflicts have emerged (1) in competition for curriculum time, power, value, time, and status $_{i}(2)$ in discussions at case conferences as to what is clinically central and what is clinically peripheral; and (3) in the recruitment, promotion, and retention of faculty (physician and nonphysician alike). Despite widespread lip service to George Engel's biopsychosocial mode ${ }^{14}$ of health and of medical care, the "bio" (that is, biological constructs) prevails over the "psychosocial." 
As a result, psychosocial factors are experienced as outside, rather than inside, authentic family medicine.

External factors, too, have helped marginalize family and broader psychosocial issues and even the physician-patient relationship itself. Since the mid-1980s, the ostensibly time-saving and cost-saving demands of managed care have placed increasingly greater constraints on family physicians. Among the first and most superficially espoused values to go are those that require time, intimacy, and caring. Attentiveness to the lived nuances of human lives and their communities is quickly sacrificed for shortcut medical and related brief mental health strategies.

There are now fewer physicians and medical educators who advocate for attention to family dynamics, for greater health care access (equity) for indigent or underserved populations, for careful integration of the complexities of sickness and healing, and for careful attention to the personal, relational side of medicine In the continuing struggles over funding, reimbursement, stature, space allocation, turf, and power in biomedicine, these advocates are far less acknowledged or rewarded for their contributions to their departments. A value-based social selection process is clearly at work. Ironically the same kinds of cultural forces that once favored the family now select for other, more biomedically-founded specializations. In both cases, the specialist orientation won out over the generalist perspective.

\section{INSIDE AND OUTSIDE: FAMILY MEDICINE'S PROBLEMATIC BOUNDARIES}

This duality is played out in the enduring conflict in family medicine over what is ours and what is theirs. The constant lure of, if not pressure from, specialists and specialization makes generalism difficult to sustain. The boundary between family medicine and what is external to us, outside ("them"), has long been highly permeable, making it difficult to construct an enduring sense of what is ours, inside ("us"). In particular, the multiple institutional constituencies that affect the training and practice of family physicians make it difficult for a sense of "us" to congeal in family medicine. Local family medicine departments are constrained by medical practice communities, state and national legislatures, college of medicine and health sciences center decision-making processes (from allocation of money to curriculum time), specialty departments and services in which family physicians must rotate and train, and a growing host of requirements from national accreditation and legitimization bodies. Local constraints on the scope of practice in family medicine include malpractice insurance, especially in obstetrics.
The development and maintenance of internal cultural continuity and a reliable cultural boundary are made difficult under the circumstances of continuous change that often become perceived as threat, attack, and intrusion. Consider the common experience of family medicine interns. Although they are formally known as family medicine interns, they generally spend little time in the family medicine department or on its clinical services. Instead, they rotate for 1 month (sometimes 2) on a sequence of medical services: surgery, emergency medicine, obstetrics, neonatal intensive care unit, pediatrics, and so on. Each service comes with new cultural and identity demands, in addition to the clinical skills, rules, and roles to learn, every first day of the month. Interns have the common feeling of being like a fish out of water, of being in places "where they need you for their 'scut work,' but they don't want you." No sooner have the interns learned the culture of the specialty service on which they are rotating, than they have to start all over again as a stranger at the beginning of the next month.

As a strategy to enhance identity, many family physicians incorporate an outside identity and use it to help define what is inside family medicine. For instance, there are numerous distinct interest groups and much internal specialization within family medicine. The discipline's ambivalence about internal specialization and the development of distinct interest groups is illustrated by the intense debate about any certificate of added qualifications (CAQs) in family medicine. Ironically, this internal fragmentation parallels and replicates the very institution of biomedicine and its American culture that many in family medicine had originally sought to reform.

Still another relationship between inside and outside lies in the common distinction between what we say and what we do, that is, between espoused and lived values. For example, I have long been told by family physicians that, "we family physicians treat patients, not diseases. That's what distinguishes us from internal medicine, med-peds, and pediatrics." In reality, this articulates an ideal position that often differs from practice. Many practitioners and teachers within family medicine unconsciously identify with the ideals and practices of specialist biomedicine while claiming to be different from them.

\section{FAMILY MEDICINE AS CULTURAL REALITY, FAMILY MEDICINE AS METAPHOR}

Clearly, the discipline of family medicine has been battered by the vicissitudes of identity in the American biomedical arena; the multiple, overlapping and conflicting views about what constitutes family medicine, 
perhaps the most central of which is the distinction between generalist and specialist; and the many historically conflicting and mutating insides within an ostensibly single culture.

As a long-time participant-observer in family medicine, I advocate trainees' and practitioners' attentiveness as much to their own professional and national cultures and identities as to those of their patients. ${ }^{5}$ This self-critical and compassionately critical attitude is as crucial to my work as an applied medical anthropologist as anything else practical that I do as a clinical teacher with family medicine residents. The identity issue pervades everything we do.

What pitfalls, then, should we avoid as we reexamine our identity in family medicine? First might be the lure of new bandwagons that promise to solve our identity problem once and for all. For instance, the allure of the role of gatekeeper to the health care system has proved to be more a trap than a long-term opportunity. Second, related to the first, is the easy appeal of new slogans. The admonition to "think family" or to "think reflectively" is not the same as painstaking, critical inquiry. To tell people how to think is a tacit prohibition against thinking itself. Third is the temptation to confuse ideology (eg, the biopsychosocial model) with actual practice, to say one thing but to mean and do another. Fourth might be the tendency to regard the appeal of specialization or expertise as narrowly unique to family medicine when in fact it is a core feature of the American cultural ethos. Finally, all of us in family medicine would do well to apply the attitude of reflective practice - that is, of thinking about what we are doing as we do it-not only to dayto-day clinical work but to contemplation of the future of the discipline itself.

To read or post commentaries in response to this article, see it online at http://www.annfammed.org/cgi/content/full/4/4/455.

Key words: Family practice; social identification; culture; social values; conflict (psychology); generalism; specialties, medical
Submitted July 27, 2005; submitted, revised, December 30, 2005; accepted January 162006.

An early version of this essay was presented as a plenary talk at the annual Society of Teachers of Family Medicine (STFM) Predoctoral Education Conference, held in San Antonio, Tex, on 28 January 2000.

Acknowledgments: I am grateful to William L. Miller, MD, MA, for his generous reading of this manuscript; and likewise to the editors of Annals of Family Medicine and the reviewers of this manuscript for their guidance and patience.

\section{References}

1. Martin JC, Avant RF, Bowman MA, et al. The Future of Family Medicine: a collaborative project of the family medicine community. Ann Fam Med. 2004;2(Suppl 1):S3-32.

2. Stein HF. Family medicine as a meta-specialty--and the dangers of overdefinition. 1981. Fam Med. 1998;30:637-641.

3. Stein HF. The Psychodynamics of Medical Practice: Unconscious Factors in Patient Care. Berkeley, Calif: University of California Press; 1985.

4. Stein HF. Polarities in the identity of family medicine: a psychocultural analysis. In: Doherty WJ, Christianson CE, Sussman MB, eds. Family Medicine: The Maturing of a Discipline. New York, NY: The Haworth Press; 1987:211-233.

5. Stein HF. American Medicine as Culture. Boulder, Colo: Westview Press; 1990.

6. Stein HF. Listening Deeply. Boulder, Colo: Westview Press; 1994.

7. Stein HF. Euphemism, Spin, and the Crisis in Organizational Life. Westport, Ct: Quorum Books; 1998.

8. Erikson EH. Identity and the Life Cycle, Selected Essays. Monograph, Psychological Issues. New York, NY: International Universities Press; 1959.

9. Erikson EH. Identity: Youth and Crisis. New York, NY: Norton; 1968.

10. Volkan VD. The Need to Have Enemies and Allies: From Clinical Practice to International Relationships. Northvale, NJ: Jason Aronson; 1988.

11. Volkan VD. Bloodlines: From Ethnic Pride to Ethnic Terrorism. Boulder, Colo: Westview Press; 1997.

12. Stephens GG. Developmental assessment of family practice: an insider's view. In: Doherty WJ, Christianson CE, Sussman MB, eds. Family Medicine: The Maturing of a Discipline. New York, NY: Haworth Press; 1987:1-21.

13. Frey JJ, 3rd. GP to FP to GP? Fam Med. 2003;35:671-672.

14. Engel GL. The need for a new medical model: a challenge for biomedicine. Science. 1977;196:129-136. 